Int. J. Electrochem. Sci., 14 (2019) $11641-11650$

Short Communication

\title{
Epoxy/Nano-SiO 2 Anticorrosion Coatings Synthesized by Different Molar Ratio of Tetraethyl orthosilicate (TEOS) and Tetramethyl orthosilicate (TMOS)
}

\author{
Shaoxiang Li $^{1,2,3}$, Jiaping Wang ${ }^{1,2,3}$, Wenjuan $Q u^{1,2,3, *}$, Jiaji Cheng ${ }^{1,2,3}$, Yunna Lei ${ }^{1,2,3}$, \\ Meng Liu ${ }^{1,2,3}$, Dong Wang ${ }^{1,2,3}$ \\ ${ }^{1}$ College of Environment and Safety Engineering, Qingdao University of Science and Technology, \\ Qingdao, 266042, P. R. China \\ ${ }^{2}$ Shandong Engineering Research Center for Marine Environment Corrosion and Safety Protection, \\ Qingdao University of Science and Technology, Qingdao, 266042, P. R. China \\ ${ }^{3}$ Shandong Engineering Technology Research Center for Advanced Coating, Qingdao University of \\ Science and Technology, Qingdao, 266042, P. R. China \\ *E-mail qwj7710@163.com
}

doi: $10.20964 / 2019.12 .06$

Received: 24 June 2019 / Accepted: 12 August 2019 / Published: 29 October 2019

\begin{abstract}
Epoxy/nano- $\mathrm{SiO}_{2}$ composite coatings were carried out by using epoxy with different TEOS/TMOS molar ratio. Nano-silica particles, which were synthesized by different molar ratio of tetraethyl orthosilicate (TEOS) and tetramethyl orthosilicate (TMOS), manifested different characteristics in particle size and modifier graft coverage. The structure was analyzed by FT-IR, XRD and SEM. The particle size of the silica was correspondingly reduced and the surface coverage of the APTES decreased with the TMOS content reduced. Thus, the particle size and surface coverage of the APTES play an important role in corrosion resistant of epoxy/nano- $\mathrm{SiO}_{2}$ composite coatings. The results showed that the composite coating had the best anticorrosion effect when the molar ratio of TEOS / TMOS was 1: 1.
\end{abstract}

Keywords: Epoxy coatings; Nano-silica; Nanoparticles; Corrosion

\section{FULL TEXT}

(C) 2019 The Authors. Published by ESG (www.electrochemsci.org). This article is an open access article distributed under the terms and conditions of the Creative Commons Attribution license (http://creativecommons.org/licenses/by/4.0/). 